\title{
A INFLUÊNCIA DO JORNALISMO NA CONSTITUIÇÃO DOS FUNDOS SOCIAIS DE CONHECIMENTO: O CASO DE MONTE ALEGRE - PR
}

\author{
Ana Flávia Braun Vieira ${ }^{\text {DD } 1}$ e Miguel Archanjo de Freitas Junior ${ }^{\text {(D) } 2}$
}

\section{Resumo}

Uma vez que o processo de civilização de qualquer sociedade é orientado pelos saberes que circulam em seu interior, este trabalho estudou a influência do jornalismo na constituição dos fundos sociais de conhecimento. Tomando a cidade-empresa de Monte Alegre (atual município de Telêmaco Borba - PR) como paradigma empírico, foi realizada a análise de conteúdo temática das crônicas de Marenfis (pseudônimo de João Marenda), publicadas em 1948 e 1964 no jornal O Tibagi, buscando conhecer aspectos dos saberes socialmente partilhados em seu espaço de circulação e da transformação comportamental local - mobilizada principalmente pelas narrativas que incitavam o medo e a vergonha. Além de elementos sócio e psicogenético específicos da figuração analisada, os resultados do estudo também indicam que as narrativas jornalísticas, ao mobilizar um conjunto de saberes específico, intermediam as experiências possíveis em seu espaço de abrangência - podendo até mesmo alterar o ritmo dos processos de civilização.

Palavras-chave: Norbert Elias; Processo civilizador; Fundo social de conhecimento; Jornalismo; Telêmaco Borba.

\section{THE JOURNALISM INFLUENCE ON THE CONSTITUTION OF SOCIAL FUNDS OF KNOWLEDGE: THE CASE OF MONTE ALEGRE - PR}

\begin{abstract}
Once the civilization process in any society is guided by the knowledge that circulates within it, this paper studied the journalism influence on the constitution of the social funds of knowledge. Taking the Monte Alegre company town (current municipality of Telêmaco Borba - PR) as an empirical paradigm, it was developed a thematic content analysis of the chronicles of Marenfis (pseudonym of João Marenda), published between 1948 e 1964 in the O Tibagi newspaper, seeking to recognize aspects of the socially shared knowledges in its circulations space and consequent behavior transformation - mobilized mainly

${ }^{1}$ Doutora em Ciências Sociais Aplicadas pela Universidade Estadual de Ponta Grossa. Professora Colaboradora do Departamento de Educação da UEPG.

${ }^{2}$ Doutor em História pela Universidade Federal do Paraná. Professor Associado da Universidade Estadual de Ponta Grossa, Setor de Ciências Biológicas e da Saúde, Departamento de Educação Física e Programa de Pós-graduação Stricto Sensu em Ciências Sociais Aplicadas.
\end{abstract}


by narratives that incited fear and shame. In addition to specific socio and psychogenetic elements of the analyzed figuration, the results also indicate that journalistic narratives, by mobilizing a specific set of knowledge, mediate the possible experiences in its circulation scope - which can even change the pace of civilization processes.

Keywords: Norbert Elias; Civilizing process; Social fund of knowledge; Journalism; Telêmaco Borba.

\section{Introdução}

O processo civilizador pode ser caracterizado como uma "mudança estrutural ocorrida em pessoas na direção de maior consolidação e diferenciação de seus controles emocionais e, por conseguinte, de sua experiência (...) e de sua conduta" (ELIAS, 2011, p. 209). Esse processo ocorre - sob determinadas condições - devido à disposição natural que os seres humanos possuem para "utilizar modelos aprendidos para refrear ou canalizar os impulsos relativamente elementares e espontâneos do organismo" (ELIAS, 1998a, p. 121). Na concepção do sociólogo Norbert Elias, que desenvolveu a teoria dos processos civilizadores, a capacidade de aprender a regular o comportamento foi determinante para que a humanidade chegasse ao estágio de desenvolvimento atual.

Os saberes que pautam o comportamento humano, em diferentes figurações, são resultantes de um longo processo de aprendizagem e pertencem a todos os homens e mulheres, que a partir dele agem, sentem e pensam. Tratase de "Um fundo histórico e em mudança recebido por cada um, que também é responsável por aumenta-lo e preservá-lo" (SÁ, 1998, p. 09). Cada figuração, no entanto, possui seu próprio fundo social de conhecimento, podendo partilhar similaridades em sua composição - especialmente em relação ao conhecimento científico - com outras formações sociais.

A construção desse fundo de conhecimento inicialmente se deu de forma mais lenta, porque menos articulada com a realidade física. Mas, ao longo das gerações, os próprios conhecimentos adquiridos estimularam o desenvolvimento da capacidade de prospecção, que paulatinamente passou a orientar - ao menos em curto prazo - os saberes a serem aprendidos pela descendência. $\mathrm{Na}$ concepção de Elias, quanto mais congruente é o conhecimento com a realidade, maior é a capacidade humana de antecipação: "Junto com o avanço do conhecimento científico desses níveis da natureza, avança a capacidade das pessoas de manipular e controlar os processos para os seus próprios fins" (ELIAS, 1998b, p.40).

É neste ponto que este trabalho propõe uma reflexão sobre a influência do jornalismo na constituição de um fundo social de conhecimento e, por extensão, acerca de sua contribuição na orientação dos processos de civilização em seu espaço de abrangência. Acredita-se que, de maneira intencional ou não, os conteúdos veiculados nos jornais contribuem para a estruturação desse 
conjunto de saberes, ao mesmo tempo em que alteram o ritmo dos processos de desenvolvimento. Dadas as relações de poder, o conteúdo publicado nos periódicos, ao lado de outros elementos aceleradores, tem contribuído para a rápida internalização de normativas comportamentais - especialmente no caso das narrativas que mobilizam o medo e a vergonha.

Nesse sentido, a figuração de Monte Alegre - PR, uma cidade-empresa de propriedade das Indústrias Klabin, foi tomada como paradigma empírico. Para estudar seu processo de civilização foi realizada a análise de conteúdo temática nas crônicas de Marenfis, publicadas entre 1948 e 1964 no jornal O Tibagi, buscando conhecer aspectos dos saberes socialmente partilhados em seu espaço de circulação e da transformação comportamental local. A escolha deste semanário está relacionada ao seu papel no ordenamento social local e a opção por Marenfis diz respeito ao conteúdo de suas crônicas, que tinham caráter explicitamente pedagógico e contribuíram para a redução de um "choque de civilização" entre os trabalhadores com diferentes níveis de autocontrole, ao estimular a homogeneização comportamental.

A adoção de uma perspectiva sociológica para estudar parcela da história da constituição do fundo de conhecimento de Monte Alegre/Telêmaco Borba, além de permitir compreender aspectos sociais e emocionais pretéritos, por vezes negligenciados na própria história oficial, possui implicações que extrapolam o contexto local e regional de investigação: ao mesmo tempo em que apresenta uma possibilidade teórico-metodológica para a produção de conhecimento histórico pautado em fontes jornalísticas, que permite contemplar a transformação das sensibilidades e comportamentos, evidencia o papel educativo do jornalismo na orientação dos saberes que balizam as existências nas figurações sob sua influência.

\section{Marco teórico e contextualização do objeto}

O sociólogo Norbert Elias foi tardiamente reconhecido pelo desenvolvimento de um conjunto de noções que possibilitam o estudo de diferentes aspectos dos processos civilizadores. Entre suas contribuições, destaca-se aquelas voltadas à sociologia do conhecimento. Para o autor, o conhecimento humano é transmitido ao longo das gerações e sua aquisição por cada indivíduo se dá por meio da aprendizagem social:

As teorias sociológicas do conhecimento têm de quebrar a tradição firmemente entrincheirada, segundo a qual cada pessoa em termos de seu próprio conhecimento é um começo. Ninguém é. Cada pessoa parte da palavra e entra na preexistente corrente de conhecimento, que ela pode melhorar ou aumentar. Trata-se sempre, entretanto, de um fundo de conhecimento já existente que avançou ou é levado a declinar (ELIAS, 1998b, p. 27-28).

Os fundos de conhecimento são presentes em todas as sociedades humanas e variam de acordo com os diferentes estágios de desenvolvimento das figurações das quais são produtos e produtores. Esse conjunto de saberes 
possui fronteiras definidas, ainda que alguns de seus membros possam trabalhar para alterá-las. Nesse ponto é fundamental considerar a interferência das relações de poder sobre o campo das experiências possíveis, uma vez que os dominantes têm a capacidade de orientar a definição dos conteúdos socialmente partilhados (ELIAS, 1994b).

Em uma perspectiva de longa duração, é possível afirmar que, inicialmente, esses conhecimentos costumam ser mais orientados pela fantasia e vão, ao longo do tempo, se direcionando para uma maior congruência com a realidade (ELIAS, 1994b), possibilitando aos indivíduos antecipar-se às demandas visando benefícios futuros. O rumo de um processo de desenvolvimento, no entanto, "nunca foi planejado como tal, mas é o resultado imprevisto de uma infinidade de ações humanas e de interações planejadas" (GOUDSBLOM, 2014, p. 75). Todavia, em um olhar mais detido, de recorte médio, é possível estudar as ações intencionais de indivíduos, grupo e/ou instituições que buscam orientar os conteúdos concernentes ao fundo comum de conhecimento.

Uma vez que os seres humanos orientam suas existências a partir dos conhecimentos que possuem, o controle desses saberes é objeto de disputa nas relações de poder. Ao contribuir para o esquecimento ou para a evidência de determinado conteúdo, os dominantes têm o poder de influenciar os processos de desenvolvimento, sejam eles civilizadores ou não. Essa influência é assim chamada porque os processos de formação do fundo social de conhecimento são resultantes de tensões, inerentes às relações de poder e aos processos de civilização em qualquer figuração. Ou seja, as intenções individuais/grupais/institucionais podem até ser inicialmente determinadas, mas seus efeitos não são previsíveis - sequer na curta duração.

A formação desse "patrimônio de saber" (ELIAS, 1998b, p. 10) pode receber a contribuição de todos os indivíduos de uma rede de interdependência específica, no entanto, determinados conteúdos são reprimidos ou esquecidos, distorcidos ou expurgados "de acordo com a distribuição de poder entre os grupos que controlam a produção e a disseminação do conhecimento" (ELIAS, 2008, p. 533), hierarquizando e excluindo certos saberes. Como a cultura da classe dominante é o padrão requisitado para o "sucesso social", os saberes e comportamentos por ela valorizados passam a ser praticados por diferentes grupos (ELIAS, 1993 e 2011). Nesse processo, os indivíduos vão aprendendo a reprimir seus impulsos, adequando suas condutas às demandas crescentes de suas redes de interdependência. A despeito de movimentos regressivos, a aprendizagem das condutas socialmente aceitáveis tem-se acelerado em ritmo progressivo, "apoiado em todo tipo de técnicas auxiliares" (ELIAS, 1998b, p. 52), como o jornalismo.

Ao fazer a mediação entre os indivíduos e as transformações do seu cotidiano, o jornalismo influencia no direcionamento dos processos históricos e na constituição das subjetividades (RIBEIRO; FERREIRA, 2007, p. 07). Esta capacidade está pautada em convenções de veracidade, nas quais o conteúdo jornalístico é tomado como verdadeiro por antecipação (BABOSA, 2007). Esse 
discurso autorizado não é imparcial ou neutro, posto que é organizado a partir dos interesses dominantes nas relações de poder (MOTTA, 2002).

O consumo dos conteúdos veiculados na imprensa é um ato culturalmente importante, pois tais informações "Estabelecem as fronteiras éticas e morais", ao mesmo tempo em que possibilitam a cada indivíduo se "resituar cotidianamente no mundo" e realizar "operações simbólicas necessárias à sedimentação de conteúdos que são contados e recontados diariamente" (MOTTA, 2002, p. 14). Por meio dos sentidos construídos pelas narrativas dos jornais, os indivíduos em interdependência orientam suas relações sociais e emocionais e aprendem comportamentos entendidos como civilizados. De acordo com Campos (2014, p. 321), que estudou o papel da imprensa regional no ordenamento social, os impressos desempenham um papel educativo contínuo, particularmente no que diz respeito ao ensinamento sobre o modo de ser".

Com base no exposto, acredita-se que os jornais, além de selecionar os conteúdos que veiculam, influenciando na estruturação do fundo de conhecimento, têm ainda a capacidade de interferir no direcionamento e no ritmo dos processos civilizadores: ao apresentar de maneira sintética um conjunto específico de conteúdos, orienta a recepção no sentido do enunciador, acelerando aprendizagens - que, sem esse tipo de pressão externa, talvez demorassem anos para acontecer (ao ritmo das demandas sociais).

Entretanto, a forma como cada sessão do jornal atua sobre os indivíduos e suas subjetividades é distinta. O caráter pedagógico do jornalismo é manifesto de maneira específica no campo da economia, da política, da cultura, etc. - até porque a forma de dirigir-se aos leitores é diferenciada. No caso das notícias, a "perseguição à objetividade" ainda é o ideal dominantes nas redações (MOTTA, 2002, p. 19). Já a subjetividade seria permitida em cadernos de caráter mais cultural e nas crônicas - espaço onde a manifestação explícita dos posicionamentos dos autores é admitida.

Especificamente sobre as crônicas, este gênero é caracterizado pelo "diálogo direto entre autor e leitor(a)", estabelecendo entre estes uma "relação de proximidade quase íntima" (SIEBERT, 2014, p. 680). O cotidiano, especialmente as quebras de rotina, é privilegiado entre os temas possíveis e a escrita costuma ter um ar despretensioso (CÂNDIDO, 1992) - o que, no entanto, não reduz seu potencial educativo. Isso porque, segundo Gouvêa (2017), as marcas verbais promovem certos efeitos e conforme o contexto e a situação de emprego das palavras, o autor "solicita uma determinada interpretação de parte do seu público destinatário (se essa interpretação se realizará de fato, é outra questão)" (MOTTA, 2013, p. 127). Dessa forma, a crônica mobiliza a audiência em relação ao conjunto de saberes que enuncia, mediando o campo das experiências possíveis e influenciando no ritmo dos processos de civilização.

\subsection{0 jornal $O$ Tibagi na cidade-empresa de Monte Alegre}

O Tibagi foi um jornal de publicação semanal que circulou na cidadeempresa de Monte Alegre a partir de 23 de novembro de 1949. Fundado por (c) (i)

Perspectivas em Diálogo, Naviraí, v. 08, n. 17, p. 345-364, maio/ago. 2021. 
Horácio Klabin, que chegou à região em meados de 1947 para atuar como Diretor Administrativo na fábrica de sua família, o semanário representou, "para a grande maioria dos operários alfabetizados a primeira leitura regular, desde que deixaram os bancos da escola primária". Segundo Vieira (2015, p. 72-73), a organização do periódico respondia às seguintes funções: "contribuir no processo de evolução de sua comunidade; (...) irradiar a luz da civilidade nos sertões; (...) noticiar, atacar e defender, bem como ensinar, instruir; (...) ser uma instituição que esclarece e a comunidade consulta para saber, elogiar e julgar".

A orientação do periódico tem relação com a história do desenvolvimento de Monte Alegre, que foi concebida como um modelo de sociedade e industrialização para o Brasil. Diferente de outras formações sociais, que avançam a partir das próprias relações sociais e emocionais, essa figuração foi construída em ocasião da instalação de uma fábrica de papel e celulose no interior do Paraná. Segundo Couto (2017, p. 199), "A história de Monte Alegre e região divide-se em antes e depois da chegada da Klabin. (...) Ela trouxe riqueza, progresso, modernidade, civilização".

A construção de uma fábrica no interior do Paraná, próxima à matériaprima, requisitou o desenvolvimento de toda a infraestrutura necessária para receber os trabalhadores e suas famílias e garantir a produção industrial. Isso, de fato, só foi possível porque desde o início das negociações para a compra da Fazenda Monte Alegre pela Klabin, em 1934, o Presidente Getúlio Vargas foi um grande entusiasta do empreendimento. Segundo Couto (2017, p. 221),

[...] nascente projeto em Monte Alegre se encaixava à perfeição na política industrial de Vargas. Substituição significativa de importações, empreendimento nacional, matéria-prima verdeamarela, maior segurança no setor de celulose e papel, impulso ao progresso de região remota, geração significativa de renda, empregos diretos e indiretos, aumento da receita pública (COUTO, 2017, p. 221).

A construção de uma fábrica de papel e celulose nacional foi uma das prioridades do governo Vargas. Como o Presidente utilizava amplamente da imprensa para fazer propaganda e legitimar seu governo, entendia que o país não poderia permanecer vulnerável ao abastecimento de papel. Segundo Assis Chateaubriand, "a fábrica de papel e celulose do Tibagi se fez, não porque os Klabin a quisessem construir naquele momento [1941], mas porque assim o entendeu exclusivamente Vargas" (apud COUTO, 2017, p. 227).

Como exemplo de progresso para o Brasil, assim foi sendo construída a cidade e a empresa em Monte Alegre. Segundo publicou O Tibagi, "Bastou que o dedo da civilização aqui tocasse e a região deserta e desconhecida em outras se transformou" (O TIBAGI, 23 jan. 1952, p. 03). Esse processo de civilização, no entanto, não ocorreu sem tensões. Em um espaço voltado totalmente para a produção industrial, onde de um momento para o outro pessoas estudadas da e na Europa passaram a conviver com operários oriundos do meio rural e das cidades vizinhas, eram supostos choques de sensibilidades. Assim, visando 
homogeneizar as condutas dentro e fora do ambiente de trabalho, uma série de medidas foram tomadas pela direção da Klabin. Entre as ações que visaram manter a ordem social - como a proibição do consumo de bebidas alcoólicas no interior de Monte Alegre e a suspensão de operários caso dormissem em serviço ou fossem desonestos -, destaca-se a criação do "Jornal da Empresa" (CUNHA, 1982, p. 07).

A publicação de avisos da empresa sobre consumo excessivo de água, distribuição de moradias, restrição da circulação de animais no perímetro urbano sob a pena de extermínio do animal e multa são alguns exemplos que permitem compreender o papel ordenador de O Tibagi na localidade. Sendo Monte Alegre um espaço isolado geograficamente, os conteúdos veiculados no jornal orientavam os limites de conhecimento da população e, por extensão, as existências em interdependência. Nesse sentido, a crônica era mais um espaço a partir do qual os indivíduos poderiam tomar conhecimento de determinados fatos sobre a localidade, informar-se sobre a atualidade e, ao mesmo tempo, ter contato com uma leitura de mundo.

\subsection{As crônicas de Marenfis em 0 Tibagi}

Marenfis é um dos heterônimos do jornalista João Marenda (1923-1990), que foi tipógrafo, redator e gerente do jornal O Tibagi. Natural de Ponta Grossa - PR, em 1948, mudou-se para Monte Alegre para trabalhar no semanário a convite da Klabin. A conquista de posições mais elevadas na hierarquia do periódico tem relação com a boa educação que recebeu nos seminários que frequentou. Segundo entrevista realizada com seus filhos, além de grande talento musical, João Marenda tinha conhecimentos em Filosofia, Latim e Português, tendo também atuado como professor nestas áreas.

Um ponto peculiar de seus escritos é a relação entre o conteúdo e o heterônimo utilizado. Quando escrevia sobre política, economia e cultura, assinava como J. Marenda. É o caso das colunas Posto de Observação e Cajadadas. Já na Crônica da Cidade, uma coluna que só saía quando havia "encomendas" ou espaço excedente no jornal, na qual escrevia sobre ocorrências verificadas em diferentes lugares de Monte Alegre, assinava como Marenfis. Acredita-se que tal distinção se dava em razão de João Marenda ser uma figura de destaque no jornal e na sociedade local, não querendo ter diretamente sua imagem associada àquele que diz "umas inocentes verdadezinhas $(. .$.$) recebidas tão hostilmente" (MARENFIS, 19$ mai. 1955, p. 02).

Segundo Marenfis, a Crônica da Cidade era motivada pelo desejo de aumentar o progresso de Monte Alegre. Para tanto, tratava de diferentes assuntos relacionados à localidade, conforme as solicitações das cartas e telefonemas recebia: "não é por simples prazer que temos tocado, por estas colunas, neste ou naquele assunto merecedor de crítica. Se assim o fazemos, é com o intento de que se corrija o que está errado" (MARENFIS, 11 out. 1950, p. 05). Em relação à recepção dos leitores, de acordo com o cronista, haviam pessoas que não gostavam nem de olhar para a coluna, enquanto outros, em 
maior número, reclamavam quando a mesma não era publicada. Dependendo o assunto abordado, gerava comentários durante toda a semana, o que na visão de Marenfis era atestado de que "a notícia alcançou seu objetivo primordial, isto é, foi lida. Lida e comentada" (MARENFIS, 11 ago. 1955, p. 02).

Seus escritos eram diretos (imperativo do pequeno espaço para a publicação) e, com frequência, usava a ironia como estratégia na produção de sentidos. Ao trazer à público determinado assunto, elogiar ou criticar, sugerir ações, recriminar comportamentos - ou seja, direcionar as aprendizagens no sentido das demonstrações afetivas socialmente aceitáveis ao empreendimento modelo - Marenfis, orientava a estruturação do fundo de conhecimento de Monte Alegre, ao mesmo tempo em que seus escritos funcionavam como pressões externas, contribuindo para a civilização das condutas no interior da cidadeempresa.

Sua contribuição para o fundo social de conhecimento da figuração de Monte Alegre variou ao longo do recorte temporal da pesquisa. Acredita-se que duas foram as motivações para essa distribuição heterogênea das publicações ao longo dos anos: a primeira tem relação com as responsabilidades de João Marenda na hierarquia do jornal (as publicações da Crônica da Cidade foram iniciadas dois meses após assumir o cargo de redator chefe, em 14 jun. 1949, e reduzidas paulatinamente, tendo como marco desta diminuição 1959, ano em que se tornou gerente do semanário) e a segunda está relacionada ao próprio desenvolvimento sociogenético local. Sendo europeu o modelo que pautou a construção da cidade-empresa de Monte Alegre, na gênese do projeto já estava inclusa a intensão de expansão daquela localidade sem a intervenção da Klabin (PIQUET, 1998). Assim, após a consolidação da produção industrial no final da década de 1940, o "Plano de Desativação" optado pela Klabin foi a progressiva transferência dos operários para outra localidade - reduzindo a necessidade da existência da crônica como um fator de ordenamento social de Monte Alegre.

\section{Metodologia}

Para estudar a influência do jornalismo na construção e disseminação de um fundo de conhecimento coletivo, a partir da publicação de sínteses, que potencialmente estimulam o ritmo de desenvolvimento dos processos sociais ao orientar as aprendizagens, foi realizada a análise de conteúdo nas crônicas de Marenfis publicadas em $O$ Tibagi. Desta forma, as todas etapas da metodologia foram comtempladas. São elas:

Na pré-análise, fase que corresponde à organização do material empírico, foram escolhidos os documentos, elencados os objetivos e elaborados os indicadores que fundamentaram a análise. Neste processo estabeleceu-se que todas as Crônicas da Cidade publicadas entre 1948 e 1964 seriam consideradas. Todavia, ao realizar a leitura flutuante neste material, foi possível observar que nem todas as crônicas tinham caráter educativo explícito. Assim, um segundo recorte foi realizado, obedecendo aos seguintes critérios: foram excluídas as crônicas sem sanções pedagógicas diretas e as quais o assunto foi abordado 
uma única vez. Por fim, o conjunto documental de análise ficou composto por 134 crônicas.

Na exploração do material, os dados brutos foram sistematizados por meio da codificação. Durante o procedimento de codificação, a partir de operações de recorte do texto, as temáticas mais frequentes foram definidas como unidades de registro. A partir desse critério, foram elencados os principais temas como unidades de registro. Ao término, foi realizada a categorização, que consiste em "uma operação de classificação de elementos constitutivos de um conjunto por diferenciação e, em seguida, por reagrupamento segundo o gênero (analogia), com critérios previamente definidos" (BARDIN, 2011, p. 147). 0 critério para a categorização foi de ordem semântica, sendo também o tema a unidade de significação. Assim, as crônicas que versaram sobre os comportamentos desejados aos frequentadores do cinema foram classificadas em "comportamento no cinema", enquanto as que elogiaram determinada conduta foram classificadas em "reforço positivo" - para citar alguns casos ilustrativos. Dessa maneira, emergiram 13 categorias, a saber:

\section{Quadro 01 - Análise de conteúdo temática das crônicas de Marenfis - Categorias.}

\begin{tabular}{|c|c|}
\hline CATEGORIA & NÚMERO DE PUBLICAÇÕES \\
\hline Comportamento coletivo & 52 \\
\hline Comportamento das mulheres & 05 \\
\hline Comportamento dos homens & 07 \\
\hline Comportamento dos jovens & 03 \\
\hline Comportamento dos motoristas & 15 \\
\hline Comportamento dos namorados & 04 \\
\hline Comportamento dos pais & 02 \\
\hline Comportamento dos trabalhadores & 02 \\
\hline Comportamento no cinema & 07 \\
\hline Educação & 05 \\
\hline Higiene & 02 \\
\hline Progresso local & 15 \\
\hline Reforço positivo & 15 \\
\hline
\end{tabular}

Fonte: Os autores (2021).

Por fim, foram realizadas as inferências. Com base nos dados obtidos nas etapas acima descritas, os conteúdos presentes nas narrativas foram evidenciados e possibilitaram inferir acerca dos sentidos presentes nas crônicas. Assim, foi possível conhecer aspectos dos saberes estimulados pela crônica, além de sua ação na transformação comportamental local.

É importante destacar que neste trabalho as crônicas foram concebidas enquanto narrativas, ou seja, "dispositivos argumentativos produtores de significados e sua estruturação na forma de relatos obedece a interesses do narrador (individual ou institucional) em uma relação direta com o seu interlocutor". (MOTTA, 2013, p. 120-121, grifo do autor). Nesta concepção, entende-se que a situação de comunicação e o contexto sociocognitivo de 
produção condicionam sua forma, seus conteúdos, pontos de vista etc. Por essa razão, "É impossível desconsiderar as manobras e artimanhas discursivas decorrentes das intenções do autor/narrador [...], sejam elas conscientes ou inconscientes", na criação de significações sociais, uma vez que têm a capacidade de "cristalizar as crenças, os valores, as ideologias, a política, a cultura, a sociedade inteira" (MOTTA, 2013, p. 121).

\section{Conhecimentos socialmente mobilizados pelas crônicas de Marenfis}

As categorias que emergiram da análise de conteúdo evidenciam aspectos dos conhecimentos mobilizados em Monte Alegre por meio das crônicas de Marenfis, para a orientação comportamental. A forma como os assuntos foram abordados demonstra aspectos da sensibilidade de João Marenda e dos interesses do grupo por ele representado. Dadas as relações de poder, as narrativas da Crônica da Cidade funcionavam como pressões, orientando as condutas na direção de seu enunciador.

Por se tratar de uma cidade-empresa, os conteúdos da crônica, via de regra, versavam sobre comportamentos tidos como favoráveis à ordem social e ao desenvolvimento industrial. Em relação aos comportamentos coletivos, Marenfis escreveu estimulando a ordem na sorveteria e no embarque de ônibus; pedindo respeito no cemitério, especialmente no dia de Finados; contrário aos atos de vandalismo; solicitando que os donos mantivessem seus cães presos; dissuadindo as pessoas de dar esmolas para quem poderia trabalhar; alertando sobre os perigos de nadar no rio Tibagi; ensinando a responder fielmente ao censo; pedindo o fim de boatos e fofocas em Monte Alegre; ensinando como se deve ajudar o próximo; contrário às pessoas que vendiam seus bens para tentar a sorte; criticando quem não trabalhava; mostrando-se contrário aos apelidos; associando civismo ao sucesso (individual e da nação); posicionando-se de maneira contrária a crendices e superstições; estimulando a filantropia; e, por fim, indicando comportamento desejável durante as eleições.

$\mathrm{Na}$ concepção representada por Marenfis, todas as mulheres, por mais que dissessem o contrário, desejavam casar-se. E as de Cidade Nova foram duramente repreendidas pelo cronista quando decidiram montar um time de futebol em 1957: "A mulher, para ser mulher, tem de ser mulher. [...] Futebol, não pode. A menos que se não faça conta de deixar de ser mulher" (MARENFIS, 28 fev. 1957, p. 05). Em relação ao comportamento dos homens, versou sobre os transtornos à família e à sociedade causados por aqueles que bebem em demasia e os estimulou a se tornarem pais amorosos, trabalhadores e inteligentes.

Já os jovens, deveriam receber melhor educação dos pais, especialmente aqueles que ficavam de traquinagem pelas ruas ou em rodinhas nas esquinas, fazendo algazarra e contando piadas de conteúdo questionável. Sobre os casais de namorados, Marenfis (17 set. 1952, p. 05) escreveu sobre os abusos cometidos pelos mesmos, que obrigavam a população montealegrense a assistir a cenas "impróprias para menores": "Desnecessário será deixarmos aqui nossa 
reprovação [...] Se dissermos que isto é feio, dificilmente há quem nos escute. Mas, creiam-nos, que, de fato, não fica bem...".

Como a reprodutibilidade da mão de obra passava pela educação dos filhos dos operários, o cronista chamou a atenção dos pais e explicou as razões pelas quais deveriam mandar os filhos à escola. A aprendizagem realizada em ambientes (in)formais de ensino transformam as condutas não apenas daqueles que estão em contato direto com os conteúdos de aprendizagem, mas, de maneira indireta, de toda a família. "As crianças são o futuro da nação" (MARENFIS, 30 ago. 1949, p. 05). A importância da educação foi reiterada com o argumento de que faria bem para os filhos e para a pátria, pois evitava o crime. Por essa razão, se possível, deveria ser iniciada já no Jardim da Infância.

Saberes em relação ao uso do cinema também foram mobilizados na Crônica da Cidade: recriminou o comportamento de uma turma de garotos que fazia barulho, batia os pés e assoviava durante a exibição do filme; dos pais que levavam seus bebês e já no início da projeção "o berreiro começava" (MARENFIS, 23 abr. 1952); daqueles que estavam quebrando as cadeiras do cinema por puro divertimento; e dos valentões que se exibiam e até ameaçavam sair no braço dentro do cinema.

A ênfase ao progresso local serviu para requisitar comportamentos compatíveis ao nível de civilização da figuração. Nas crônicas foram destacadas as construções pujantes de Monte Alegre, como as casas de alvenaria ofertadas aos trabalhadores pela empresa, a usina hidrelétrica e o estádio de futebol, entre outras. "Tudo isto denota o nosso crescente e acelerado progresso" (MARENFIS, 27 set. 1949, p. 05). Segundo Marenfis, mesmo Cidade Nova "já alcançou um grau inevitável de progresso e um lugar de destaque no cenário paranaense" (MARENFIS, 03 jan. 1950) .

Um recurso para disseminar determinados conhecimentos e incitar condutas foi a publicação de crônicas reforçando positivamente determinadas posições. Marenfis enalteceu as "senhoras e senhoritas, que trabalham com amor e desprendimento", num elogio à filantropia (MARENFIS, 11 out. 1949); parabenizou os brasileiros dignos, honrados e patriotas; congratulou os operários que fizeram o Curso de Aperfeiçoamento e se tornaram melhores em suas profissões; elogiou os comportamentos ordeiros durante o carnaval, posto que não houve "Nenhum incidente, nenhuma nota dissonante no acordo das brincadeiras. Tudo dentro da maior ordem possível" (MARENFIS, 28 fev. 1950, p. 06). Ainda em relação ao carnaval, ressaltou aqueles indivíduos ajuizados que logo em seguida voltaram à rotina e ao trabalho. Também reconheceu o esforço das "verdadeiras mães", incentivando a "boa maternidade" (MARENFIS, 16 mai. 1951, p. 05); louvou a iniciativa de jovens ao organizar um grupo de teatro; valorizou a postura de jogadores do time local, que, pelo bom comportamento, honravam a torcida; aplaudiu a iniciativa de festividades saudáveis nos Clubes locais; engrandeceu a prática de jardinagem; e afirmou ter sido "uma surpresa muito agradável" a conduta da plateia durante a apresentação de uma orquestra sinfônica. Segundo o autor, mencionava elogiosamente tais acontecimentos porque eram raros e "dignos de registro" (MARENFIS, 27 jan. 1955, p. 02). 
Por fim, restam ainda três categorias, que serão analisadas mais detidamente na sessão a seguir, posto que mobilizaram o medo e a vergonha, estimulando a rápida internalização comportamental. São elas: comportamento dos motoristas, comportamento dos trabalhadores e higiene.

\subsection{Recurso ao medo e à vergonha para a orientação das condutas}

A opção por aprofundar neste artigo as categorias comportamento dos motoristas, comportamento dos trabalhadores e higiene tem relação com seu potencial de inferências, uma vez que permitem observar a utilização do medo e da vergonha como mecanismos de pressão social e transformação comportamental.

Dado o monopólio da indústria sobre as principais fontes de renda em Monte Alegre, o medo de perder a posição social (emprego e todos os benefícios advindos deste) era presente. Assim, era preciso antecipar-se às demandas em busca de prestígio na figuração (representada por uma promoção no trabalho ou algum tipo de reconhecimento/gratificação dos chefes). Nesse sentido,

A paixão momentânea e os impulsos afetivos são, por assim dizer, reprimidos e dominados pela previsão de aborrecimentos posteriores, pelo medo de uma dor futura, até que, pela força do hábito, esse medo finalmente contenha o comportamento e as inclinações proibidos, mesmo que nenhuma outra pessoa esteja fisicamente presente, e a energia dessas inclinações seja canalizada numa direção inócua, sem o risco de qualquer aborrecimento (ELIAS, 1993, p. 227).

Nesse movimento, as atividades mais instintivas, muitas vezes já naturalizadas, aprendidas na vivência anterior a Monte Alegre, foram "progressivamente excluídas do palco da vida comunal e investidas de sentimentos de vergonha" (ELIAS, 1993, p. 193-194), conforme a orientação do jornal - com destaque para a Crônica da Cidade.

De acordo com Elias, a vergonha pode ser sintetizada como uma espécie de ansiedade automática que se reproduz no indivíduo, de acordo com a ocasião, por força do hábito. Esta reação automatizada ocorre, na maioria das vezes, por medo da degradação social, de se colocar em uma posição de inferioridade. Para o autor, este sentimento está relacionado ao fato de que "a pessoa que a sente fez ou está prestes a fazer alguma coisa que a faz entrar em choque com as pessoas a quem está ligada de uma forma ou de outra, e consigo mesma, com o setor de sua consciência mediante o qual controla a si mesma" (ELIAS, 1993, p. 242). Todavia, a expressão da vergonha não ocorre somente em relação à opinião social preponderante, mas, em especial, no interior no indivíduo, em um conflito consigo mesmo, uma vez que aprendeu a partilhar desta mesma opinião. No curso do processo civilizador, a pacificação diminui os medos exteriores, ao passo que crescem, na mesma medida, os interiores.

A partir destas considerações, é possível problematizar as crônicas que versaram sobre o comportamento dos motoristas, mobilizando o medo e a 
vergonha. A publicação desta temática foi recorrente porque novas tecnologias pressupõem um conjunto de saberes - neste caso fomentado pelo jornal. Enquanto os motoristas não internalizaram determinados conhecimentos relativos à direção, as crônicas serviram como objeto de pressão. Os pontos mais frequentes foram: solicitando obediência aos limites de velocidade e às placas de sinalização, versando sobre a necessidade de maior cuidado na direção na região das escolas e apresentando-se contrário à utilização de buzinas a vácuo.

Em 1949, 1950 e novamente em 1951, o excesso de velocidade e os possíveis danos causados em caso de acidentes foram temas da Crônica da Cidade. Sendo a "falta de noção de responsabilidade" entre os motoristas atitude frequente, Marenfis (14 nov. 1951, p. 03) escreveu: "afinal de contas, isto não é nada bonito. É até caso de polícia...". A referência à polícia possivelmente estimulou a célere adequação comportamental. Em menos de um mês o cronista publicou sobre os resultados:

De há muito que nos vimos debatendo, destas colunas, contra o excesso de velocidade em nossas ruas. [...] A ação enérgica do sr. sub delegado, porém, não se fez esperar por muito tempo, e, agora, com as providências tomadas, estamos mais calmos. Sabemos que não se registrarão mais desastres por excesso de velocidade (MARENFIS, 12 dez. 1951, p. 05).

Resolvida a questão da elevada velocidade com a qual trafegavam em Monte Alegre, em 1956, a Crônica da Cidade atuou sobre outro problema relativo aos motoristas: as buzinas a vácuo, especialmente quando utilizadas de madrugada. Além de usar o sono dos trabalhadores e das criancinhas como argumento para dissuadir a utilização noturna do instrumento, também mobilizou a vergonha por meio da ironia: "quem inventou essa trombeta para ser usada em caminhões deve ter umas orelhas, quero dizer, uns ouvidos! duros como queixo de burro" (MARENFIS, 16 fev. 1956, p. 04).

Já na edição seguinte de Crônica da Cidade, publicou-se carta assinada por Vilém Willer, um dos engenheiros-chefe da Klabin e presidente do Lions Clube local. A missiva tratava da "satisfação de vermos continuar essa campanha, que é em favor da coletividade" e "dos esforços comuns para convencer os nossos motoristas que a buzina é destinada para a estrada" (WILLER, 23 fev. 1956, p. 04). Willer argumentou também comparando Monte Alegre com cidades modernas, onde já havia proibição do uso do equipamento, e concluiu dizendo: "Por que então não fazer em Monte Alegre uma cidade de alto nível de civilização, sem proibir? Em Monte Alegre sempre existiu o princípio de não mandar, mas pedir, e de não obedecer, mas sim colaborar" (WILLER, 23 fev. 1956, p. 04).

Em 01 mar. 1956, uma semana depois, em letras miúdas, Marenfis voltou a escrever sobre a campanha contra as buzinas a vácuo. Desta vez, trouxe ao fundo de conhecimento coletivo que Nova Iorque (EUA) também adotou tal medida e que puniria os infratores com multas. Ao apresentar como exemplo para a população um local tido como referente de civilização e mencionar a (c) (i) 
possibilidade de perdas financeiras pelo eventual uso das buzinas, os leitores, dotados deste novo saber, puderam antecipar-se à aplicação deste tipo de sanção em Monte Alegre e adequaram seus comportamentos. No ano seguinte, as pressões sobre os motoristas já eram outras:

Bem dizem que o castigo vem a cavalo.

Todos devem estar lembrados de nossa ojeriza contra das chamadas buzinas a vácuo.

Elas desapareceram, coitadas! Às vezes, a gente chega até a ficar com saudades delas. [...]

Antes a buzina a vácuo. Antes ela, um objeto quase insignificante, do que um caminhão inteiro que faz barulho por todos os lados (MARENFIS, 11 jul. 1957, p. 04).

Além de demonstrar a célere adequação às pressões nesta esfera, o excerto ilustra um aspecto característico do processo civilizador: a contínua demanda por novas sensibilidades e comportamentos. Dada a capacidade dos indivíduos em aprender, ao menos em parte, aspectos do fundo de conhecimento pertencente às suas redes de interdependência, a busca por distinção movimenta os processos de desenvolvimento. Isso significa dizer que, quando determinado número de pessoas já atingiu um patamar comportamental socialmente requisitado, novas formas de apresentação são reclamadas. Sendo este um processo constante, o jornal O Tibagi e a crônica de Marenfis cumpriram papel pedagógico no desenvolvimento de outras sensibilidades em sua figuração de abrangência - a exemplo da nova campanha contra os caminhões barulhentos.

Em relação ao comportamento dos trabalhadores, em 1950, Marenfis mobilizou o medo e a vergonha tanto de patrões quanto de empregados, ao escrever sobre a atuação dos balconistas locais - que lhe feria a subjetividade. Nas palavras do cronista: "Pela má vontade estampada em suas fisionomias, ao nos servirem, temos a impressão de que somos, para eles, nós os fregueses, uns inoportunos, uma espécie de inimigos dos senhores balconistas" (MARENFIS, 10 out. 1950, p. 05). Citou também a brutalidade como outro defeito dos atendentes e sugestionou a demissão dos mesmos: "fazemos um apelo aos responsáveis pelos nossos diferentes estabelecimentos, para que ponham um paradeiro nesse lamentável estado de cousas, que, dia a dia, conforme temos observado, tende a piorar" (MARENFIS, 10 out. 1950, p. 05).

A crônica da semana seguinte retomou o assunto e permitiu inferir que os escritos de Marenfis sobre esta esfera geraram polêmica. Segundo o autor, "Não supúnhamos que aquelas palavras fossem causar tamanha celeuma", responsabilizando o resultado das eleições pela reação hostil diante de "umas inocentes verdadezinhas" (MARENFIS, 11 out. 1950, p. 05). Fez ressalvas às "exceções honrosas", que deveriam servir como exemplo, e não mudou sua argumentação, reafirmando-a. Disse ainda que sua única satisfação no ato de criticar era observar sua contribuição para a melhoria local, "mesmo se tenha de pisar nos calos dos barbeiros, dos motoristas, dos balconistas e de outros" (MARENFIS, 23 nov. 1951, p. 15). 
Ao criticar o comportamento dos balconistas, Marenfis evidenciou aspectos das relações de poder local: a atitude dos trabalhadores pode ter sido interpretada como uma prática de resistência e a atuação do cronista, incitando a demissão dos mesmos, um mecanismo para reequilibrar as relações de poder em favor de sua classe. O apelo realizado aos responsáveis pelos estabelecimentos para que resolvessem o problema dos balconistas maleducados serviu como coerção tanto para patrões como para funcionários. Sendo necessária a autorização da Klabin para a realização de quaisquer atividades comerciais dentro de seu território privado (WILLER, 1997), os empregadores correriam o risco de perder sua licença caso seus funcionários não fossem competentes ao gosto representado por Marenfis. Diante da possibilidade de perda de prestígio, inclusive material, todos os envolvidos se mobilizaram para adequar suas condutas às demandas publicadas no jornal.

Ao abordar a falta de higiene nos barbeiros e cabelereiros, Marenfis mobilizou uma série de conhecimentos para chamar a atenção de seus leitores na direção de sua argumentação: "Julgamos anti-higiênico que o resto da espuma, usada em um freguês, sirva para o seguinte. Deveriam, pois, as nossas barbearias possuir água encanada e uma pia, o que, indiscutivelmente, tornaria mais higiênico o serviço dos barbeiros" (MARENFIS, 23 nov. 1949, p. 07). Explicou que a falta de higiene estava na ausência de uma pia, onde fosse possível lavar o pincel e a espumadeira constantemente. Ao término, concluiu com uma pressão: "Oxalá, dentro de pouco tempo, tenhamos o prazer de fazer outra crônica, não criticando e sim louvando os barbeiros" (MARENFIS, 23 nov. 1949, p. 07).

Este caso é ilustrativo porque permite observar possíveis efeitos das crônicas entre a população. Além da sanção direta destinada aos barbeiros e cabeleireiros, as narrativas acabavam estimulando a supervisão mútua entre os habitantes da cidade-empresa e, portanto, a constante autodisciplina em relação à higiene ou aos demais temas pautados na Crônica da Cidade. Sobre a transformação comportamental decorrente da cobrança social, Elias (1993, p. 251) escreveu:

Dada essa estrutura de interdependências, a tensão social produzia uma forte tensão interna nos membros [...]. Esses receios mergulharam em parte, embora nunca inteiramente, nas zonas inconscientes da personalidade, delas reemergindo apenas em forma modificada, como automatismos específicos de autocontrole. [...] esse medo social [...] constituiu uma das mais poderosas forças motrizes do controle social que todos os membros da classe superior exerciam sobre si mesmos e sobre outros membros do círculo que viviam.

Trazer ao conhecimento do público leitor determinado tema e, por conseguinte, sugestionar transformações comportamentais eram práticas correntes nos escritos de Marenfis. Em 1952, outra vez mobilizou a população à supervisão mútua, agora ao apontar falhas de higiene na padaria. Como usual em suas narrativas, primeiro indicou o problema - chamando a atenção para o 
fato, caso alguém ainda não tivesse notado; e, depois, apontando e/ou cobrando soluções: "A mesma pessoa que recebe o dinheiro é a que entrega os pães, utilizando-se para isto - é claro - das mãos. Não está certo, em absoluto. Temos certeza, entretanto, que essa falha será prontamente sanada" (MARENFIS, 30 abr. 1952, p. 05).

Ao publicar crônica chamando a atenção da "Padaria local - seção de vendas", nominalmente, direcionou o olhar da população para a (ausência de) higiene do lugar. Diante disso, sob a ameaça de perder seus clientes - e, pior, perder a licença de funcionamento na propriedade da Klabin - , foram adequadas as condutas do estabelecimento aos padrões de higiene representados na crônica de Marenfis. Esse tipo de sanção pública servia como castigo exemplar. Dessa forma, em um movimento de antecipação, os proprietários adequavam a higiene de seus estabelecimentos mais conforme às demandas das classes dominantes - temendo a exposição diante de toda a cidade-empresa.

Em uma análise geral das crônicas problematizadas, é possível observar que a mobilização de conhecimentos que incitaram o medo e a vergonha, visando a transformação comportamental, foram frequentes nos anos iniciais da Crônica da Cidade. Acredita-se que a distribuição temporal das crônicas tem relação com as próprias aprendizagens mediadas pelo jornal. No decurso das publicações, em conjunto com as demais narrativas de $O$ Tibagi e em combinação com outros mecanismos de exercício do poder, um conjunto de informações passou a circular em Monte Alegre, influenciando os saberes pertencentes ao fundo de conhecimento comum daquela figuração. Ao longo das narrativas, foram sendo construídas a moral, as leis, os costumes, as crenças, os valores morais e políticos, bem como as formas socialmente aceitáveis de comportamento - não como uma cópia fiel das intencionalidades de seus idealizadores, mas como resultado das tensões e relações de poder inerentes aos processos de desenvolvimento.

Por fim, segundo as considerações de Elias (1993, p. 236, grifo do autor), é preciso ponderar que a civilização não "envolve apenas mudanças no 'conhecimento', transformações de 'ideologias', em suma, alterações no conteúdo da consciência, mas mudanças em toda a constituição humana, na qual as ideias e os hábitos de pensamento são apenas um setor". Isso significa dizer que as adequações comportamentais aqui apontadas respondem a um movimento mais amplo transformações sociais e de personalidade em Monte Alegre.

\section{Considerações finais}

O processo civilizador "constitui uma mudança na conduta e sentimentos humanos rumo a uma direção muito específica" (ELIAS, 1993, p. 193). Segundo Norbert Elias (1998b), o que torna possível esse processo é a capacidade biológica que os humanos possuem para aprender na experiência com seus pares. Os conteúdos das aprendizagens são oriundos de um fundo comum de saberes pertencente a cada grupo, sendo indispensáveis para adquirir qualquer conhecimento. Esse fundo, a despeito de movimentos de reorientação de sua 
direção, "vem crescendo em ritmo progressivo", assegurado em todo tipo de técnicas auxiliares (ELIAS, 1998b, p. 52). Entre os diferentes elementos que podem interferir no ritmo das mudanças supracitadas, este trabalho dedicou-se à contribuição do jornalismo na construção e disseminação de um fundo social de conhecimento.

Ao abordar um assunto de determinada maneira, silenciar outras informações e dizer o "correto" proceder - para citar alguns exemplos -, os jornais têm a capacidade de orientar os conteúdos pertencentes ao fundo social de conhecimento das figurações de sua abrangência e, portanto, o próprio processo civilizador. No caso do jornal O Tibagi e da Crônica da Cidade, escrita por Marenfis (heterônimo de João Marenda), as publicações acerca dos comportamentos socialmente desejáveis coagiam à transformação comportamental - que, talvez, sem esse tipo de pressão levaria anos para se modificar. Isso significa dizer que no lugar de aguardar as próprias relações de interdependência entre os residentes de Monte Alegre irem reclamando, no ritmo dos contatos, certos comportamentos, as narrativas do jornal - que representavam as sensibilidades do grupo dominante nas relações de poder da cidade-empresa -, ao lado de outros mecanismos de controle, aceleraram a civilização daquela localidade.

Sendo Monte Alegre uma "atmosfera semifeudal" (PASSOS, 2013, p. 142), onde praticamente todas as esferas da vida eram monopólios da indústria, para tomar parte naquela figuração era necessária a "sujeição de sua conduta a padrões específicos de controle dos afetos" (ELIAS; SCOTSON, 2000, p. 26). Nesse sentido, as narrativas de Marenfis mobilizaram um conjunto de saberes e mediaram as experiências possíveis na cidade-empresa, influenciando no conteúdo e ritmo dos processos de desenvolvimento. Como a análise das fontes permitiu observar, a adequação comportamental na direção do enunciador foi estimulada pelo recurso ao medo e à vergonha. Diante da possibilidade da perda do emprego - que em uma cidade-empresa é sinal de existência social -, com base nos conhecimentos adquiridos nas leituras do jornal e na circulação social de informações, os indivíduos se anteciparam às demandas, adequando suas condutas para manter ou elevar seu prestígio social.

Por fim, resta dizer que o empreendimento em Monte Alegre, que constitui um processo social em si mesmo, demandou um novo nível de civilização aos diferentes indivíduos que passaram a tomar parte naquela figuração. Isso não significa dizer que os operários oriundos de regiões rurais eram incivilizados perto dos técnicos europeus. Tratavam-se de níveis diferentes de autocontrole e que foram sendo homogeneizados ao longo de diferentes processos de aprendizagem ocorridos na cidade-empresa. Nesse contexto, o jornal foi apenas um dos elementos que contribuiu para a transformação da constituição psíquica dos "montealegrense", tornando os trabalhadores e a própria indústria exemplo para o Brasil de meados do século $\mathrm{XX}$. 


\section{REFERÊNCIAS}

ACERVO DA FAMÍLIA MARENDA. Biografia. s/d.

BARBOSA, Marialva. História cultural da imprensa: Brasil, 1900-2000. Rio de Janeiro: Mauad X, 2007.

BARDIN, Laurence. Análise de conteúdo. São Paulo, SP: Edições 70, 2011.

CAMPOS, Raquel Discini de. Imprensa e educação feminina em zona pioneira: o caso do Noroeste Paulista (1920-1940). Revista Brasileira de História.

São Paulo, v. 34, n. 67, 2014.

CÂNDIDO, Antonio. et al. A crônica: o gênero, sua fixação e suas transformações no Brasil. Campinas: Ed. da Unicamp, 1992.

CARVALHO, Dinizar Ribas de. Telêmaco Borba o município: história política da capital do papel e da madeira. Curitiba, 2006.

CORREIA, Telma de Barros. De vila operária a cidade-companhia: as aglomerações criadas por empresas no vocábulo especializado e vernacular. R. B. Estudos urbanos e regionais, n. 4, 2001.

COUTO, Ronaldo Costa. A saga da família Klabin-Lafer. Rio de Janeiro: Chermont Editora, 2017.

CUNHA, Anacília Carneiro da. Homem de Papel: Análise Histórica do Trabalhador das Indústrias Klabin do Paraná de Celulose S/A (1942-1980). Dissertação de mestrado. Curitiba, UFPR, 1982.

ELIAS, Norbert. A sociedade dos indivíduos. Rio de Janeiro: Zahar, 1994a.

ELIAS, Norbert. Envolvimento e alienação. Rio de Janeiro: Bertrand Brasil, 1998b.

ELIAS, Norbert. O Processo Civilizador, volume 1: uma história dos costumes. 2. ed. Rio de Janeiro: Zahar, 2011.

ELIAS, Norbert. O Processo Civilizador, volume 2: formação do Estado e civilização. Rio de Janeiro: Zahar, 1993.

ELIAS, Norbert. Sobre o tempo. Rio de Janeiro: Zahar, 1998a.

ELIAS, Norbert. Sociologia do conhecimento: novas perspectivas. Sociedade e Estado, Brasília, v. 23, n. 3, p. 515-554, set./dez. 2008. 
ELIAS, Norbert. Teoría del símbolo. Un ensayo de antropologia cultural. Barcelona: Península, 1994b.

ELIAS, Norbert.; SCOTSON, John L. Os estabelecidos e os outsiders: sociologia das relações de poder a partir de uma pequena comunidade. Rio de Janeiro: Jorge Zahar Ed., 2000.

GOUDSBLOM, Johan. O fogo e os combustíveis na história da humanidade. In: GEBARA, A. ; LEÃO, A. B. Norbert Elias \& Educação. Belo Horizonte: Autêntica, 2007.

MARENDA, João Geraldo.; MARENDA, Júlio César. Entrevista concedida à Ana Flávia Braun Vieira. 12 dez. 2019.

MOTTA, Luiz Gonzaga. Análise crítica da narrativa. Brasília: Editora Universidade de Brasília, 2013.

MOTTA, Luiz Gonzaga. Por uma antropologia da notícia. Revista Brasileira de Ciências da Comunicação. v. 25, n. 02, 2002.

PASSOS, John dos. O Brasil em Movimento. São Paulo: Saraiva, 2013.

QUINTEIRO, Tania. Processo civilizador, sociedade e indivíduo na teoria sociológica de Norbert Elias. Belo Horizonte: Argvmentvm, 2010.

RIBEIRO, Ana Paula Goulart; FERREIRA, Lucia Maria Alves. Apresentação. In: RIBEIRO, Ana Paula Goulart; FERREIRA, Lucia Maria Alves. (Orgs.). Mídia e memória: a produção de sentidos nos meios de comunicação. Rio de Janeiro: Mauad X, 2007.

SÁ, Alvaro de. Nota do Tradutor. In: ELIAS, Norbert. Envolvimento e alienação. Rio de Janeiro: Bertrand Brasil, 1998.

SIEBERT, Silvânia. A crônica brasileira tecida pela história, pelo jornalismo e pela literatura. Linguagem em (Dis)curso - LemD, Tubarão, SC, v. 14, n. 3, p. 675-685, set./dez. 2014.

VIEIRA, Ana Flávia Braun. A aceleração do processo civilizador e a possibilidade de redução do recorte temporal de análise. Anais do 170 Simpósio Internacional Processos Civilizadores. Londrina: UEL, 2018.

VIEIRA, Ana Flávia Braun. Análise do discurso fundador de Telêmaco Borba no jornal O Tibagi (1948-1964). Ponta Grossa, PR. Dissertação de mestrado. Universidade Estadual de Ponta Grossa, 2015.

VIEIRA, Ana Flávia Braun. Jornalismo e a duração dos processos civilizadores: análise da adequação comportamental e da formação de 
uma segunda natureza em Monte Alegre - PR (1942- 1964). Tese

(Doutorado em Ciências Sociais Aplicadas) - Universidade Estadual de Ponta Grossa, Ponta Grossa, 2020.

\section{FONTES}

Jornal O Tibagi, edições entre 1948 e 1964.

Recebido em: 27 de fevereiro de 2021. Aceito em: 06 de maio de 2021. Publicado em: 30 de junho de 2021. 